\title{
O ensino de programação para dispositivos móveis utilizando o MIT-App Inventor com alunos do ensino médio
}

\author{
Antonio Braz Finizola, Ewerton Henning Souto Raposo, Maelso Bruno Pacheco \\ Nunes Pereira, Wescley Sobrinho Gomes, Ana Liz Souto O. de Araújo, Flávia \\ Veloso C. Souza
}

Centro de Ciências Aplicadas e Educação - Universidade Federal da Paraíba (UFPB) Rua da Mangueira, s/n - CEP 58.297-000 - Rio Tinto - PB - Brasil \{antonio.finizola, maelso.bruno, ewerton.raposo, wescley.gomes,
analiz, flavia\} ddce.ufp..br

\begin{abstract}
Teaching programming is important and should not be taught only to computer science students. Several studies have shown the importance of developing skills related to programming with students at school level. This paper presents the experience report obtained from planning, implementation and evaluation of a course teaching programming using MIT App Inventor platform. The results indicate strategies that involve problem-solving, use of analogies and to promote individual challenges are useful to promote teaching of programming.
\end{abstract}

Resumo. $O$ ensino de programação é importante, e não deveria ser uma atividade restrita apenas a estudantes de Computação. Diversos trabalhos apontam a relevância de desenvolver competências relacionadas à programação com estudantes em idade escolar. Neste contexto, este trabalho apresenta o relato de experiência obtido a partir do planejamento, aplicação e avaliação de um curso de ensino de programação utilizando a plataforma MIT App inventor. Os resultados apontam que o aprendizado de programação por alunos do ensino médio de modo eficaz é influenciado pelo uso de estratégias que envolvam a resolução de problemas, uso de analogias com o cotidiano e que promovam desafios individuais.

\section{Introdução}

Esse artigo apresenta o relato de um curso de ensino de programação para estudantes do ensino médio usando uma metodologia e linguagem que possibilitasse ao aluno desenvolver aplicações para dispositivos móveis. Partiu-se da hipótese que os alunos sentiriam-se mais motivados se as aplicações desenvolvidas fossem utilizadas por eles mesmos em seus dispositivos. Segundo Wolber (2014) o ensino de programação deve ocorrer de modo significativo, prazeroso e deve ser realizado a partir da construção de aplicações que tenham utilidades práticas no mundo real.

A inserção do ensino do pensamento computacional e práticas de programação no contexto escolar trazem benefícios para o desenvolvimento do aluno conforme relata (SCAICO et al, 2013, p.93) "este tipo de educação permite o desenvolvimento de diversas capacidades que contribuem para melhorar o raciocínio lógico dos estudantes". Outra razão para inserir o ensino de programação nas escolas seria que tal proximidade 
pode contribuir para mostrar aos alunos novas possibilidades de uso das tecnologias que habitualmente manuseiam. Além de apoiar o desenvolvimento de habilidades de abstração, raciocínio lógico, decomposição e resolução de problemas.

Escolheu-se a plataforma App Inventor por a mesma apresentar os conceitos de programação de um modo atraente e significativo para os alunos. Além isso, é uma plataforma que permite abstrair a complexidade do código presente nas linguagens de programação tradicionais (GOMES e MELO, 2013). O App Inventor é uma plataforma de programação orientada a design para a criação de aplicações para a plataforma Google Android (smartphones e tablets), desenvolvida pelo MIT - Massachusetts Institute of Technology em parceria com a Google Inc. É uma linguagem que possibilita o desenvolvimento de aplicativos baseada na conexão de blocos de comandos, o que facilita o aprendizado de quem não tem conhecimento avançado em programação. Em adição, oferece recursos para que esses aplicativos explorem as muitas funcionalidades interativas de um dispositivo Android, como reconhecimento de voz, GPS, acelerômetro e conexão com a Web.

Nesse contexto, este trabalho está organizado da seguinte maneira: a seção 2 apresenta a plataforma App Inventor; a seção 3 faz a descrição do planejamento do curso; a seção 4 discute os resultados; e a seção 5 apresenta as considerações finais.

\section{A plataforma App Inventor}

A plataforma App Inventor possibilita que a aprendizagem de conceitos elementares de programação ocorra de forma significativa, uma vez que os conceitos são trabalhados de modo intuitivo e motivador. A plataforma fornece a possibilidade dos estudantes praticarem conceitos de algoritmos para elaborarem aplicativos que serão utilizados em seus dispositivos móveis.

Programar utilizando o App Inventor requer conhecer os dois recursos principais que o compõem: o App Inventor Designer e o Blocks Editor. O App Inventor Designer é uma janela executada no browser, onde se constrói a interface com o usuário da aplicação, determinando quais componentes (imagens, animações, botões, sons) serão escolhidos para essa aplicação. O Blocks Editor é onde é realizada a etapa de programação propriamente dita, a qual é representada pela união de pedaços de instruções, no estilo de peças de quebra-cabeças. Cada componente do Designer tem um conjunto de instruções inerentes dentro do Blocks Editor. As instruções do Blocks Editor apresentam procedimentos e estruturas (laços de repetição, listas, estruturas condicionais, funções, operadores matemáticos e lógicos), instruções e eventos de interações com o celular (vibração, som, acelerômetro) dos componentes que estão sendo utilizados no Designer. Dessa forma, o App Inventor utiliza programação guiada a eventos, onde as interações com o dispositivo se refletem em respostas no aplicativo e vice-versa.

O App Inventor permite que o usuário conecte o smartphone no computador e, à medida que uma aplicação vai sendo construída, acompanhe as modificações, testando no dispositivo em tempo real e recebendo um feedback imediato. Através disso, o aluno pode aprimorar suas percepções de lógicas de programação e também observar se as ações executadas ocorreram conforme desejado. 
O App Inventor dispõe de um site ${ }^{1}$, que contém diversas informações sobre a plataforma. As informações estão organizadas em tutoriais de aprendizado e técnicas de ensino de programação para professores e fóruns de discussão, blogs, notícias e eventos relacionados à utilização da plataforma em todo o mundo.

\section{Descrição das atividades do Curso}

Inicialmente foi realizado o planejamento do curso, estruturado para ocorrer em quatro aulas com duração de 3 horas cada. Todo o material foi elaborado tendo como base a metodologia disponível no site do App Inventor. Assim, foram elaborados os planos de aula e as apostilas, bem como, foram selecionados e adaptados os exercícios que seriam realizadas durante o curso.

A primeira aula teve o objetivo de apresentar e instruir os alunos a utilizarem a ferramenta. Nesse encontro foi apresentado o ambiente App Inventor, destacando suas características, funcionalidades e os processos básicos para execução de desenvolvimento de um projeto. Em um segundo momento, foi apresentado como configurar o computador e o dispositivo móvel, bem como a utilização do recurso Designer e do Blocks Editor. Ainda nesse encontro, foi desenvolvido o aplicativo "Hello World", recomendado na plataforma. Para desenvolver esse aplicativo foi necessário criar um botão e, em seguida, programá-lo, de modo que quando tocado, emita-se um som. Este aplicativo foi desenvolvido buscando introduzir e praticar os conceitos aprendidos nesta aula.

$\mathrm{Na}$ segunda aula foram introduzidos os recursos de vibração, o uso dos conjuntos de itens (listas), o sensor acelerométrico, e como criar itens aleatórios. Para aplicação desses conceitos, foi proposto aos alunos o desenvolvimento do aplicativo "Magic 8-Ball", apresentado na plataforma. O aplicativo "Magic 8-Ball" simula previsões de respostas a perguntas feitas pelo usuário. Para ensinar os conceitos de lista e aleatório, foram apresentados exemplos conhecidos dos alunos e analogias do cotidiano.

Durante o terceiro encontro foram introduzidos novos conceitos de programação (variáveis, laços e sprites), mostrando suas utilidades no desenvolvimento do aplicativo "Mole Mash". Inspirado em um jogo clássico, esse aplicativo tem como objetivo encontrar e tocar na toupeira que surge aleatoriamente na tela. O jogador pontua quando tocar na toupeira antes que ela desapareça. Com essa atividade foi possível aplicar os conceitos de laços de repetição e somadores, além do conceito de vibração visto na aula anterior. Esses conceitos foram trabalhados a partir do seguinte problema: como mover a toupeira de posição de forma contínua durante a execução do aplicativo? Para decidir a posição que a toupeira aparece na tela foi relembrado o conceito de números aleatórios aprendidos na segunda aula.

$\mathrm{Na}$ quarta aula foi apresentado o conceito de variáveis. A aula foi iniciada com a exposição de problemas que levavam os alunos a refletir sobre a necessidade de armazenar valores. A partir dessa dinâmica foi explicado o conceito de variáveis. Para praticar o conceito de variáveis, foi retornado o aplicativo da aula anterior, o "Mole Mash", e proposto que os alunos pensassem em uma solução para guardar a pontuação 
obtida pelo jogador no momento em que ele acertar a toupeira. Foi mostrado também que o valor de uma variável pode ser alterado. Isso permite que, a cada vez que o jogador acertar a toupeira, o valor da variável deve ser aumentado, utilizando o conceito de incremento. Nessa aula, os alunos concluíram os aplicativos, e foram incentivados a iniciarem a elaboração de outros aplicativos para seus dispositivos móveis.

\section{Discussão dos Resultados}

Participaram do curso 20 alunos do $1^{\circ}$ ano do ensino médio de uma escola pública estadual da cidade de Rio Tinto/PB. Os alunos inscritos possuíam tablet educacional adquiridos na escola e já tinham noções de algoritmos. O curso foi ministrado no laboratório da Universidade Federal da Paraíba, na cidade de Rio Tinto/PB, durante o mês de novembro de 2013. Dos vinte alunos inscritos, dezoito concluíram todas as atividades propostas no curso.

A turma mostrou-se motivada e ansiosa em ver o aplicativo desenvolvido executando em seus próprios tablets. Em alguns momentos, a ansiedade era tanta que os alunos não dedicavam tempo para pensar e propor soluções para os problemas propostos, desejavam ver o resultado rapidamente. Nesse momento, foi trabalhada a importância de interpretar e resolver o problema, e de compreender os conceitos envolvidos nesse processo.

De um modo geral, a plataforma App Inventor mostrou-se apropriada para atingir o objetivo proposto, que foi ofertar um curso de programação direcionada a uma plataforma de fácil interação e que possibilitasse um feedback rápido durante a construção de algoritmos com um contexto visual. O simulador virtual da plataforma possibilitou a realização de testes em tempo real da aplicação e permitiu uma melhor percepção dos alunos quanto ao comportamento do aplicativo, e ao modo que cada bloco de comando, associado aos componentes de design, gerava os eventos na tela do celular.

Ressalta-se a importância do uso de analogias no ensino dos conceitos de programação. Em todos os momentos do curso, buscou-se associar tema do cotidiano aos assuntos teóricos que foram abordados. Destaca-se que foi importante encontrar recursos e exemplos conhecidos dos alunos, pois atribuiu significado real aos conceitos trabalhados. Como ponto negativo, destaca-se o idioma da plataforma estar em inglês. Isso dificultou em alguns momentos os alunos localizar botões e recursos dentro da plataforma.

\section{Considerações finais}

Este trabalho apresentou o relato de experiência de uma ação que buscou promover a introdução de conceitos de programação fazendo uso de atividades lúdicas direcionadas a alunos do ensino médio de uma escola pública. A execução do curso mostrou a importância do uso de métodos e ferramentas que ajudem o aluno a visualizar o resultado prático dos conceitos utilizados. Os resultados apontam o feedback como fator importante para o aprendizado dos conteúdos e para o desenvolvimento de modo mais eficaz dos conceitos de abstração, desenvolvimento de estratégias de resolução de problemas, bem como uma maneira de desafio individual (conseguir realizar com êxito a atividade proposta). 
Os resultados desse curso apontam que para que ocorra o aprendizado de programação por alunos do ensino médio de modo eficaz é necessário o uso de estratégias que envolvam a resolução de problemas e que promovam desafios individuais de forma atrativa. Logo, ensinar um conceito complexo com métodos de aprendizagem dinâmicos e lúdicos não é uma tarefa simples. É necessário buscar formas diversificadas de utilizar recursos motivacionais e analogias que despertem o interesse dos alunos e facilite o aprendizado dos conceitos de programação.

Como trabalho futuro, pretende-se investigar e propor novas metodologias para aplicar o App Inventor no desenvolvimento de abstração, raciocínio lógico e resolução de problemas por meio da programação em alunos do ensino médio. Em outro trabalho futuro, pretende-se integrar o desenvolvimento de aplicativos que abordem conteúdos de disciplinas do ensino médio para uso nos tablets educacionais, distribuídos pelas escolas estaduais da Paraíba.

\section{Referências}

GUISS, A. "Google App Inventor: o criador de apps para Android para quem não sabe programar" (2011). Disponível em:<http://www.tecmundo.com.br/google/11458google-app-inventor-o-criador-de-apps-para-android-para-quem-nao-sabe programar.htm>. Acesso em: 11 jul. 2014.

WOLBER, D. "App Inventor.org - App building for everyone” (2009). Disponível em: $<$ http://www.appinventor.org>. Acesso em: 11 jul. 2014.

Massachusetts Institute of Technology. "MIT App Inventor" (2014). Disponível em $<$ http://appinventor.mit.edu/>. Acesso em: 30 jun. 2014.

GOMES, T. C. S; MELO, J. C. B. App Inventor for Android: Uma proposta construcionista para experiências significativas de aprendizagem no ensino de programação. Anais do IV Simpósio Hipertexto e Tecnologias na Educação: Redes Sociais e Aprendizagem. Recife. 2012.

GOMES, T. C. S; MELO, J. C. B. . O Pensamento Computacional no Ensino Médio: Uma Abordagem Blended Learning. Anais do XXXIII Congresso da Sociedade Brasileira da Computação. Maceió. 2013

SCAICO, P. D.; LIMA, A.A.; SILVA, J. B. B.; AZEVEDO, S. ; PAIVA, L. F.; RAPOSO, E. H.; ALENCAR, Y.; MENDES, J. P.; SCAICO, A. Ensino de Programação no Ensino Médio: Uma Abordagem Orientada ao Design com a linguagem Scratch. Revista Brasileira de Informática na Educação, Volume 21, 